\title{
Fluxo de ração avícola em silos prismáticos com tremonha excêntrica
}

\author{
Marcilene V. da Nóbrega ${ }^{1}$ \& José W. B. do Nascimento ${ }^{1}$
}

1 UFCG/CCT/DEAg, Av. Aprígio Veloso 882, Bodocongó, Campina Grande, PB, CEP 58109970, Fone: (83) 33101482
E-mail: marcilenenobrega@yahoo.com.br; wallace@deag.ufcg.edu.br

Protocolo 56 - 23/10/2003 - Aprovado em 17/3/2005

\begin{abstract}
Resumo: Na avicultura atual, o uso de silos verticais para armazenagem de ração avícola nas fábricas e nas granjas, é fator fundamental, pois garantem produto de qualidade e rapidez no processo de descarga; entretanto, são detectados diversos problemas no armazenamento e no processo de escoamento da ração, devido às falhas no projeto dos silos, tendo em vista serem negligenciadas as propriedades de fluxo dos produtos, como conseqüência do não conhecimento da teoria de fluxo. Objetivou-se, com este trabalho, analisar o tipo de fluxo em silo prismático com descarga excêntrica para dois tipos de ração avícola. Determinaram-se as propriedades físicas (teor de gordura, teor de umidade e granulometria) e as de fluxo (ângulo de atrito interno, efetivo ângulo de atrito interno, ângulo de atrito do produto com a parede, densidade em função da consolidação, função fluxo e fator fluxo). A análise do fluxo foi feita visualmente e através de seqüências fotográficas, variando a seção transversal de descarga, relação altura/lado e tempo de armazenamento. Com os resultados, verificou-se que a tremonha tronco piramidal com descarga excêntrica proporciona fluxo de massa para as rações analisadas.
\end{abstract}

Palavras-chave: descarga, avicultura, consolidação

\section{Flow of poultry ration in prismatic silos with excentric hopper}

\begin{abstract}
In the current poultry industry, the use of vertical silos for storage of avian poultry ration in the factories and in the farms is a fundamental factor, since they guarantee quality of product and rapid ness in the discharge process. However, several problems are detected in the storage and in the discharge of the ration due to the flaws in the project of silos, in which the flow properties of the products are neglected as a consequence of lack of knowledge of the flow theory. The objective of this work was to analyse the type of flow in prismatic silo with exentric discharge for two types of rations. The physical properties (fat content, moisture content and granulometry) and flow properties of (angle of internal friction, effective angle of internal friction, angle of friction of the product with the wall, density as a function of the consolidation, function flow and factor flow) were determined. The flow analysis was made visually and through photographic sequences, varying the discharge cross sectional area, ration height/side and storage time. The results demonstrated that the hopper pyramidal log with exentric discharge provided mass flow for the analyzed rations. The type of flow was influenced by the discharge cross sectional area and by the storage time.
\end{abstract}

Key words: discharge, aviculture, consolidation

\section{INTRODUÇÃO}

A agroindústria brasileira cresceu de forma acentuada nos últimos anos garantindo ao Brasil destaque mundial. Nesta perspectiva, o setor avícola garante, ao País, lugar de destaque quanto à produção de carne de frango. De acordo com a Associação Brasileira dos Produtores e Exportadores de
Frango (ABEF, 2003) o Brasil, com uma produção de carne de frango, em 2002, de 7.449 mil toneladas, é o segundo maior produtor de carne de frango do mundo, perdendo apenas para os Estados Unidos. No mercado de ração pré-fabricada, a avicultura é responsável por $56 \%$ do total interno consumido (Nogueira Júnior et al., 2002) e de acordo com informações da AVISITE (2003), contribuiu com $2 \%$ do Produto Interno Bruto, no ano de 2002. 
O êxito na avicultura depende, basicamente, do fornecimento de uma alimentação balanceada ao frango, em todas as etapas de crescimento, para garantir boa conversão alimentar (Nascimento, 1996). Este processo vai desde a matriz reprodutora até a fabricação do alimento, que garanta carne de qualidade. Desta forma, é conveniente toda atenção no processo de armazenagem e na expedição da ração nas fábricas, uma vez que esses produtos apresentam diferentes propriedades que afetam de forma intrínseca, o comportamento durante o processamento e armazenamento. Os silos são utilizados em larga escala em fábricas de ração, por se tratar de estruturas que garantem, se bem projetadas, a qualidade do produto durante bom tempo e além de facilitar o processo de sua distribuição.

A ração avícola possui, em sua composição, teores energéticos e protéicos significativos, que lhe são adicionados por meio de óleos ou produtos oleaginosos que, por sua vez, proporcionam sérios problemas durante o processo de descarga dos silos.

O fluxo em silos pode ocorrer de duas formas: por fluxo de funil, em que, durante a descarga, o material tende a formar um canal até o orifício de descarga, com zonas estáticas, e o fluxo de massa, no qual o produto fluirá e não existirão zonas estáticas (Jenike, 1964; Ooi et al., 1998; Zhong et al., 2001).

Diversos trabalhos realizados com análise de fluxo identificaram o arco coesivo e o efeito tubo como sendo os problemas mais comuns que ocorrem em silos. Jenike (1964), Roberts (1987), Drescher et al. (1995) definiram o arco como a formação espontânea de uma abóbada sobre o orifício de descarga. Bandeira (1997) realizou testes em um modelo de silo prismático industrial, com ração avícola e detectou a formação do arco coesivo e o efeito tubo. Nóbrega (2003) utilizando o mesmo silo e rações avícolas com granulometrias diferentes também verificou a formação do arco coesivo.

Outra característica que pode proporcionar problemas de fluxo é o fato de que a ração, dentro da escala granulométrica, é um produto pulverulento e, algumas vezes, coesivo, o que exige, dos projetistas, cuidados especiais no dimensionamento de silos que evitem a formação de arcos coesivos e tubos.

Tecnologia é desenvolvida para facilitar o processo de descarga em silos e, dentre elas, está a excentricidade na tremonha que, de acordo com Rotter (1998) é utilizada em algumas situações, com o propósito de simplificar o processo de descarregamento dos produtos armazenados, porém ao longo do tempo de armazenamento podem ocorrer problemas de fluxo, que são comuns e de soluções onerosas; daí, a preocupação de muitos pesquisadores em desenvolver trabalhos experimentais que simulem, através de protótipos ou de modelos reduzidos, as formas mais desfavoráveis que ocorrem durante o armazenamento, para que se possa desenvolver silos que não acarretem problemas de fluxo. Geralmente, os testes são realizados em escala reduzida, não gerando adversidade quando a situação é convertida para prática. Os modelos reduzidos são muito utilizados devido ao baixo custo e permitem que se multipliquem todos os parâmetros que influenciam na descarga do silo, na situação real (Garnier, 1998).

Pretende-se, com este trabalho, analisar o tipo de fluxo em silo prismático com descarga excêntrica para dois tipos de ração avícola; tem-se, ainda, como objetivos específicos, a determinação das propriedades físicas (teor de gordura, teor de umidade e granulometria) e as propriedades de fluxo (ângulo de atrito interno, efetivo ângulo de atrito interno, ângulo de atrito do produto com a parede, densidade em função da consolidação, função fluxo e fator fluxo).

\section{MATERIAL E MÉTODOS}

A determinação das propriedades de fluxo, o teor de umidade, a granulometria e a análise do comportamento de fluxo das rações, foram desenvolvidos no Laboratório de Construções Rurais e Ambiência - LaCRA, do Departamento de Engenharia Agrícola da Universidade Federal de Campina Grande. A determinação do teor de gordura foi realizada no Laboratório de Apoio Multidisciplinar da EMBRAPA - Algodão, Campina Grande, PB, e utilizados dois tipos de ração avícola, correspondentes às diferentes fases de crescimento.

Em função da viabilidade econômica do projeto e da funcionalidade, utilizou-se um silo em modelo reduzido (Figura 1A), confeccionado em acrílico, com chapas de espessura 1,7 $\mathrm{mm}$; sua seção transversal é quadrada, com $340 \mathrm{~mm}$ de lado e altura total $1800 \mathrm{~mm}$, dividida em três módulos iguais, cada um com altura de $600 \mathrm{~mm}$, fazendo-se três relações altura/lado iguais a 1,76, 3,5 e 5,3. As paredes dos módulos foram conformadas no sentido horizontal, em ziguezague, com inclinação de $70^{\circ}$. A tremonha utilizada para a realização do ensaio foi do tipo troncopiramidal excêntrica, com orifício de descarga quadrado (Figura 1B); esta possui duas inclinações horizontais diferentes: $\mathrm{a}_{1}=$ $71,1^{\circ}$ e $a_{2}=85,5^{\circ}$ e com $25 \%$ de excentricidade. Na confecção da tremonha usou-se o mesmo material do corpo do silo além de três seções transversais de descarga (seções transversais de descargas (STD) 1,2 e 3): $\mathrm{STD} 1=42,25 \mathrm{~cm}^{2}, \mathrm{STD} 2=64 \mathrm{~cm}^{2} \mathrm{e}$ $\mathrm{STD} 3=100 \mathrm{~cm}^{2}$.

\section{Teor de umidade e de gordura}

Determinou-se o teor de umidade pelo método oficial da estufa a $105^{\circ} \mathrm{C}$, com variação de até $3^{\circ}$, durante $24 \mathrm{~h}$, efetuando-se

A.

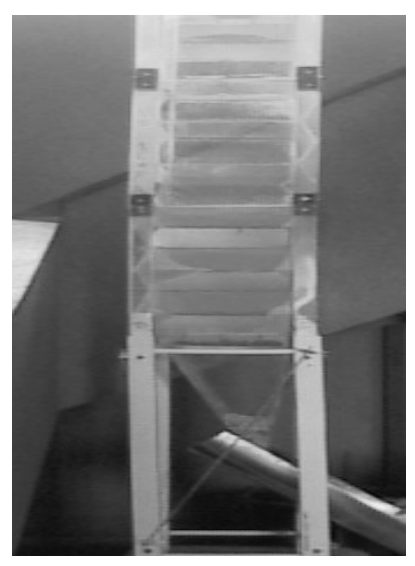

Figura 1. Modelo reduzido do silo prismático industrial (A) e tremonha tronco piramidal excêntrica (B) 
três repetições, enquanto o teor de gordura foi através do Método de Randall (1974).

\section{Granulometria}

A classificação granulométrica se deu em função das dimensões das partículas, através do peneiramento, para o que se utilizou um conjunto de peneiras, que variaram de 2,8 a 0,105 $\mathrm{mm}$, no total de 9 , além de agitador elétrico, durante $10 \mathrm{~min}$, com $80 \mathrm{rpm}$.

\section{Determinação das propriedades de fluxo instantâneas e com consolidação de 12 h}

Determinaram-se as propriedades de fluxo variando o tempo de consolidação e se utilizaram dois tempos de consolidação: instantâneo ( $\mathrm{TI}=0$ h) e com consolidação (T2=12 h).

Fez-se a determinação das propriedades de fluxo através do ensaio de cisalhamento direto, com a metodologia proposta por Milani (1993) utilizando-se o equipamento de cisalhamento direto por translação TSG 70-40, conhecido como Jenike Shear Cell. O ensaio de cisalhamento direto consistiu em duas etapas: no pré-cisalhamento e no cisalhamento. As cargas utilizadas no pré-cisalhamento, foram 10,7 e $5 \mathrm{~kg}$ e no cisalhamento, 7, 5 e 3,5 kg para um pré-cisalhamento de 10, 5, 3,5 e $2 \mathrm{~kg}$ para um pré-cisalhamento de 7 e 3,5, 2 e $1 \mathrm{~kg}$ para pré-cisalhamento de $5 \mathrm{~kg}$. Para as propriedades instantâneas fez-se este procedimento, instantaneamente, e com a consolidação de 12 $\mathrm{h}$, após realizado o pré-cisalhamento.

\section{Análise do fluxo}

Analisou-se, através de seqüências fotográficas, o fluxo instantâneo $(\mathrm{T} 1=0 \mathrm{~h})$ e com consolidação $(\mathrm{T} 2=12$ h). O silo era carregado de forma concêntrica e intercalado com camadas do produto tingido, para que se pudesse ter melhor visualização melhor do escoamento e do comportamento da simetria do fluxo do produto, após a abertura do orifício de descarga. Foram utilizadas combinações de seção do orifício de descarga e as relações alturas lado.

\section{RESULTADOS E DISCUSSÃO}

\section{Teores de umidade e de gordura}

Os resultados obtidos para a determinação do teor de umidade e de gordura encontram-se na Tabela 1, observandose que o teor de umidade da ração 1 é superior ao da ração 2 , enquanto o mesmo procedimento não é observado para os teores de gordura.

Como as rações usadas pertencem a fases distintas de crescimento do frango, ocorreu diferença entre os teores de gordura; esta diferença entre os teores de umidade se deve às características higroscópicas dos produtos utilizados na sua composição. De acordo com Torres citado por Bandeira (1997), a percentagem de gordura adequada em rações avícolas não

Tabela 1. Valores dos teores de umidade e de gordura

\begin{tabular}{ccc}
\hline Produto & Teor de Umidade (\%) & Teor de Gordura (\%) \\
\hline Ração 1 & 12,94 & 6,99 \\
Ração 2 & 11,90 & 7,24 \\
\hline
\end{tabular}

deve ultrapassar $10 \%$ e o teor de umidade deve variar entre 5 e $10 \%$. Por outro lado, os resultados encontrados neste trabalho para os teores de umidade e de gordura, não foram muito diversas dos valores de Bandeira (1997), concluindo-se, daí que, para ração avícola, o teor de gordura adicionado pelos fabricantes está na ordem de 5 a $10 \%$ e o de umidade ultrapassa os $10 \%$, suficientes, portanto, para provocar arcos coesivos, fazendo-se necessário então se determinar as propriedades físicas em função dessas variáveis.

\section{Granulomeria}

Os resultados obtidos com os ensaios granulométricos encontram-se na Figura 2. Constata-se que as duas rações possuem o maior percentual retido na peneira de malha, 0,59 mm, seguida, da peneira 1,0 mm. Calil Júnior (1984) propôs classificar-se os produtos cujos diâmetros das partículas se encontram no intervalo de $0,297 \leq \mathrm{D}_{\mathrm{p}} \leq 1,0 \mathrm{~mm}$, como produtos pulverulentos e/ou pulverulentos coesivos. Desta forma, classificam-se as duas rações com esta característica. Nascimento (1996) em ensaios realizados com rações e farelo de trigo, verificou que os maiores percentuais ficaram retidos na peneira de malha $0,50 \mathrm{~mm}$ e, seguindo a mesma classificação proposta por Calil Júnior (1984), classificou tais produtos como pulverulentos a pulverulentos coesivos; da mesma forma, Bandeira (1997) classificou dois tipos de ração estudadas; portanto, as rações avícolas estão nesta faixa granulométrica e podem ser classificadas como produto pulverulento e/ou pulverulento coesivo.

Embora as duas rações possuam teores de gordura considerados com valores altos, não se verificaram formações de pequenas esferas durante o processo de peneiramento. Segundo Nascimento (1996) essas esferas, que são formadas devido à presença de gordura, podem mascarar os resultados da classificação granulométrica.

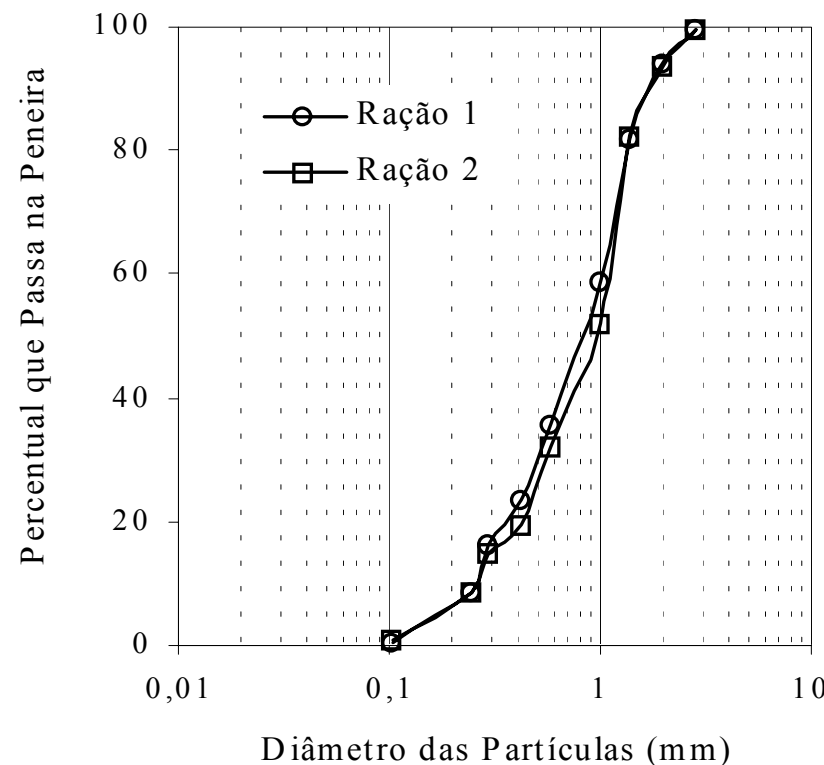

Figura 2. Curva granulométrica das rações 1 e 2, em função do diâmetro da partícula e do percentual que passa nas peneiras 


\section{Propriedades de fluxo instantâneas e com consolidação de $12 \mathrm{~h}$}

Os resultados das propriedades de fluxo instantâneas e com consolidação de $12 \mathrm{~h}$, estão na Tabela 2.

Tabela 2. Propriedades de fluxo

\begin{tabular}{|c|c|c|c|c|c|c|c|}
\hline \multirow{2}{*}{ Produto } & \multicolumn{2}{|c|}{$\phi_{\mathrm{i}}\left({ }^{\circ}\right)$} & \multicolumn{2}{|c|}{$\phi_{\mathrm{e}}\left({ }^{\mathrm{o}}\right)$} & \multicolumn{2}{|c|}{$\phi_{\mathrm{w}}\left({ }^{\mathrm{o}}\right)$} & \multirow{2}{*}{$\gamma\left(\mathrm{kg} \mathrm{m}^{-3}\right)$} \\
\hline & $\phi_{\mathrm{il}}$ & $\phi_{\text {iu }}$ & $\phi_{\mathrm{el}}$ & $\phi_{\mathrm{eu}}$ & $\phi_{\mathrm{wl}}$ & $\phi_{\mathrm{wu}}$ & \\
\hline & \multicolumn{7}{|c|}{ Instantâneas (T1 = 0 h) } \\
\hline Ração1 & 33 & 39 & 43 & 44 & 18 & 20 & 810 \\
\hline Ração2 & 43 & 46 & 46 & 49 & 17 & 19 & 820 \\
\hline
\end{tabular}

Consolidação $(\mathrm{T} 2=12 \mathrm{~h})$

\begin{tabular}{llllllll} 
Ração1 & 40 & 45 & 49 & 51 & 18 & 20 & 820 \\
Ração2 & 46 & 48 & 49 & 51 & 17 & 19 & 830 \\
\hline
\end{tabular}

$\phi i$ - ângulo de atrito interno; $\phi$ e - ângulo efetivo de atrito interno; $w$ - ângulo de atrito do produto com a parede; $\gamma$ - massa específica; $\phi_{i 1}$ - ângulo de atrito interno inferior; $\phi_{i u}$ - ângulo de atrito interno superior; $\phi$ - ângulo efetivo de atrito interno inferior; $\phi$ - ângulo efetivo de atrito interno superior; $\phi_{\mathrm{wl}}$ - ângulo de atrito do produto com a parede inferior; $\phi_{\mathrm{wu}}$ - ângulo de atrito do produto com a parede superior

Os ângulos de atrito interno instantâneo e com consolidação de $12 \mathrm{~h}$ da ração 1 , variaram no intervalo de 33 a $39^{\circ}$ e de 40 a $45^{\circ}$, respectivamente; para a ração 2 , os resultados dos ângulos de atrito interno instantâneo e com consolidação de $12 \mathrm{~h}$ ficaram no intervalo de 43 a $46^{\circ}$ e de 46 a $48^{\circ}$, respectivamente. Os efetivos ângulos de atrito interno instantâneo e com consolidação de $12 \mathrm{~h}$ da ração 1 , permaneceram nos intervalos de 43 a $44^{\circ}$ e 49 e $51^{\circ}$, respectivamente; já a ração 2 obteve resultados para o mesmo ângulo instantâneo e com consolidação de 12 h que se firmaram entre 46 e $49^{\circ}$ e 49 e $51^{\circ}$. Observase, para as duas rações, que o tempo de armazenamento contribui para aumentar os ângulos de atrito internos e ângulos efetivos de atrito interno. A ração 2 obteve resultados para os ângulos de atrito internos e ângulos efetivos de atrito interno superiores aos da ração 1, (Tabela 2), visto que o teor de gordura da ração 2 é superior ao da ração 1 , fato observado também por Bandeira (1997).

Bokhoven \& Lohnes (1989) utilizaram uma metodologia de ensaio diferente para realizar testes com farinha de soja; eles consideraram nos ensaios, $1 \mathrm{~h}$ de consolidação como instantâneo e encontraram o ângulo de atrito interno de $46^{\circ}$; para uma consolidação de $22 \mathrm{~h}$, este mesmo ângulo foi de $53^{\circ}$. Nascimento (1996) determinou as propriedades de fluxo para diversos produtos, entre eles dois tipos de ração avícola, no qual encontrou ângulos de atrito interno variando entre $43 \mathrm{e}$ $45^{\circ}$ e os ângulos efetivos de atrito interno entre 48 e $53^{\circ}$. Bandeira (1997) encontrou, em ensaios com rações avícolas ângulos de atrito interno no intervalo de 40 a $44^{\circ} \mathrm{e}$ ângulos efetivos de atrito interno entre 36 e $48^{\circ}$. Nascimento (1996) e Bandeira (1997) determinaram apenas as propriedades de fluxo instantâneas.

Verifica-se coerência entre os resultados encontrados por Nascimento (1996) e Bandeira (1997) com os dados apresentados, por se tratar de produtos com características semelhantes e mesma metodologia de ensaio. Os ângulos de atrito interno dos três autores variaram entre 33 e $46^{\circ}$ e os ângulos efetivos de atrito ficaram entre $36 \mathrm{e} 53^{\circ}$.
Analisando-se os resultados dos ângulos de atrito do produto com a parede obteve-se, na ração 1, valor superior em relação à ração 2 , por se tratar da ração que possui maior quantidade de finos, Figura 2 causando desta forma, maior adesão do produto com a parede do silo. O material utilizado para a realização do ensaio foi o acrílico, pelo fato de ser o material utilizado na confecção de modelos reduzidos. Bandeira (1997) determinou ensaios com o mesmo material e produto com características semelhantes e encontrou este ângulo variando de 13 a $16^{\circ}$.

A densidade consolidada da raçãol instantânea foi de $810 \mathrm{~kg} \mathrm{~m}^{-3} \mathrm{e}$, para consolidação de $12 \mathrm{~h}$, de $820 \mathrm{~kg} \mathrm{~m}^{-3}$. A ração 2 apresentou densidade consolidada instantânea de $820 \mathrm{~kg} \mathrm{~m}$ ${ }^{3} \mathrm{e}$ com consolidação de $12 \mathrm{~h}$ ficou em $830 \mathrm{~kg} \mathrm{~m}^{-3}$. O aumento da densidade das duas rações com o tempo de consolidação, foi devido ao tempo em que as rações ficaram sob estado de tensão.

Nascimento (1996) encontrou, em ensaios realizados com rações avícolas, valores de densidades consolidadas instantâneas variando de 710 a $830 \mathrm{~kg} \mathrm{~m}^{-3}$. Bandeira (1997) determinou, para produtos similares, densidades consolidadas instantâneas que variaram de 706 a $734 \mathrm{~kg} \mathrm{~m}^{-3}$. A metodologia utilizada para determinação da densidade consolidada foi a mesma usada pelos autores citados; no entanto, observa-se que os resultados foram diferentes, já que esta propriedade é influenciada pela granulometria, teor de gordura, teor de umidade e carga de consolidação, que variam dentro do mesmo produto, tornando diferentes as densidades.

Com os resultados das tensões máximas de consolidação $\left(\sigma_{1}\right)$ e das resistências não confinadas $\left(f_{c}\right)$, determinaram-se as funções fluxo das rações 1 e 2. Na Figura 3 observam-se as funções fluxo instantâneas $(\mathrm{FF})$ e com o tempo $\left(\mathrm{FF}_{\mathrm{t}}\right)$ da ração 1 .

Verifica-se, na Figura 3, que as funções fluxo adquiriram comportamento côncavo, de acordo com Roberts (1987) este tipo de curva indica produtos cujas tensões aumentam rapidamente; em conseqüência, aumentam também as tensões de consolidação. A função com tempo de consolidação de $12 \mathrm{~h}$ $\left(\mathrm{FF}_{\mathrm{t}}\right)$ ficou logo acima da função fluxo instantânea para as duas

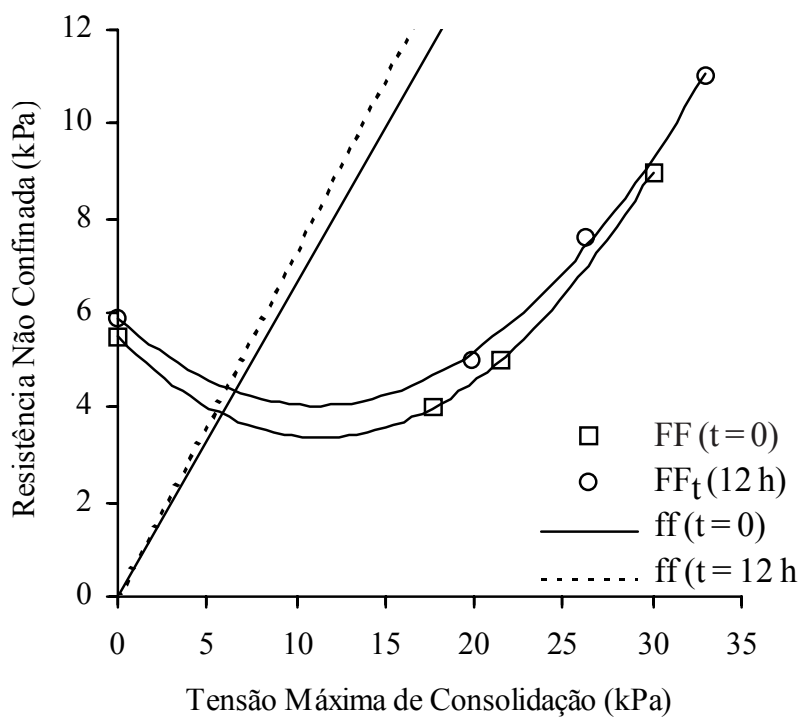

Figura 3. Função fluxo no tempo - ração1 
rações, (Figuras 3 e 4). De acordo com Benink (1989) isto ocorre porque há aumento de tensões no processo de consolidação.

A Figura 4 corresponde à função fluxo da ração 2, cujo comportamento convexo corresponde, de acordo com Roberts (1987), a um produto coesivo.

A determinação do fator fluxo foi feita com o método de Jenike (1964). Nas Figuras 3 e 4 encontram-se representados os fatores fluxo das rações $1 \mathrm{e} 2$, respectivamente; para a ração 1, o fator fluxo de T1 foi 1,46 e de T2, 1,36. A ração 2 obteve, para T1, o fator 1,42 e, para T2, o fator fluxo de 1,31. O fator fluxo depende da inclinação da tremonha, do efetivo ângulo de atrito interno e do material com que foi confeccionado o silo. $\mathrm{O}$ arc tan $(\mathrm{ff})^{-1}$ é a inclinação da reta que parte da origem do gráfico de $\mathrm{FF}$ e define o fator fluxo da tremonha (ff). Não houve muita diferença entre esses valores de ff para as duas rações, devido à pequena diferença existente entre os ângulos efetivos de atrito internos. $\mathrm{O}$ tempo de armazenamento não interferiu no fator fluxo(ff).

Não foi possível dimensionar o orifício de descarga através da BMHB (1985) para a ração 2, pois como se verifica na Figura 4, o fator fluxo não intercepta a função fluxo. Para esses casos, a literatura sugere dimensioná-lo através das dimensões das partículas. Com relação a ração 1 foi possível se obter a dimensão pro orifício de descarga sendo igual a $105 \mathrm{~mm}$ para o tempo $\mathrm{T} 1=0$ e $113 \mathrm{~mm}$ para $\mathrm{T} 2=12 \mathrm{~h}$. Desta forma, a área da seção transversal de descarga para os dois casos chega a mais de $100 \mathrm{~cm}^{2}$ compatível, portanto, com os resultados experimentais.

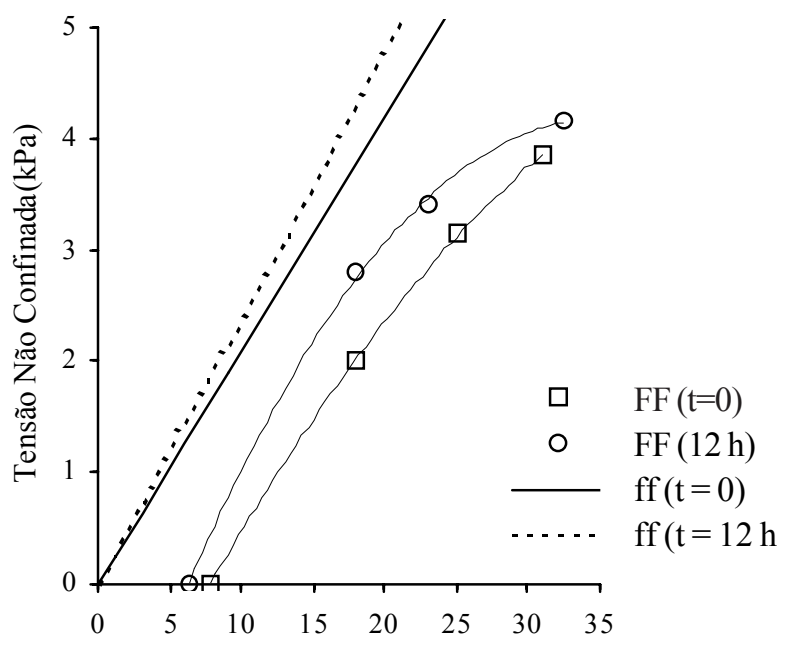

Tensão Máxima de Consolidação(kPa)

Figura 4: Função fluxo no tempo - ração 2

\section{Análise do fluxo}

As análises do comportamento do fluxo das rações estudadas foram originadas de observações visuais e registradas através de seqüências fotográficas. A Tabela 3, contém os resultados obtidos para o comportamento do fluxo, instantâneo e com tempo de consolidação de $12 \mathrm{~h}$ das duas rações.

A análise do fluxo foi realizada para as duas rações levandose em consideração o tempo de armazenamento instantâneo $(\mathrm{T} 1=0 \mathrm{~h})$ e com consolidação $(\mathrm{T} 2=12 \mathrm{~h})$.
Tabela 3. Ocorrência do tipo de fluxo durante a descarga para relação $\mathrm{H} / \mathrm{L}=1,76, \mathrm{H} / \mathrm{L}=3,5 \mathrm{e} \mathrm{H} / \mathrm{L}=5,3$ respectivamente

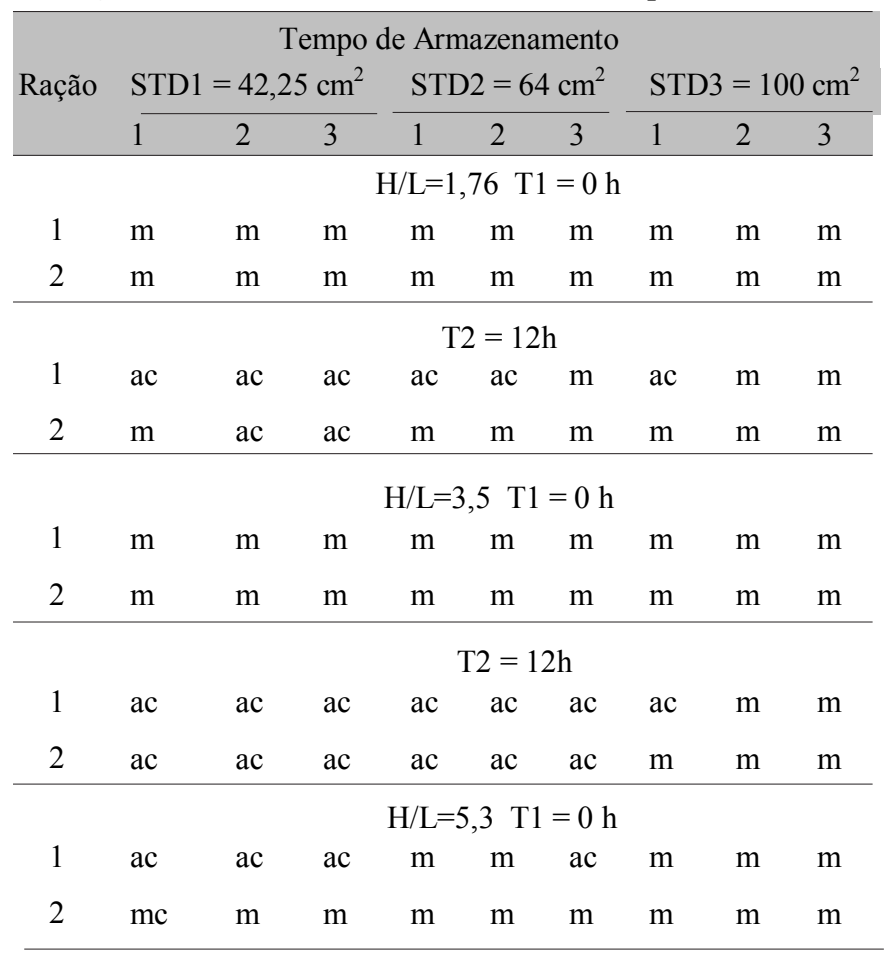

$$
\mathrm{T} 2=12 \mathrm{~h}
$$

\begin{tabular}{|c|c|c|c|c|c|c|c|c|c|}
\hline 1 & $\mathrm{ac}$ & $\mathrm{ac}$ & $\mathrm{ac}$ & $\mathrm{ac}$ & $\mathrm{ac}$ & ac & $\mathrm{ac}$ & $\mathrm{m}$ & $\mathrm{ac}$ \\
\hline 2 & ac & ac & ac & $\mathrm{ac}$ & $\mathrm{ac}$ & $\mathrm{ac}$ & $\mathrm{m}$ & $\mathrm{m}$ & $\mathrm{m}$ \\
\hline
\end{tabular}

\section{Fluxo instantâneo}

Produto: ração 1 e relação altura/lado: 1,$76 ; 3,5$ e 5,3: Para a ração 1 ocorreu fluxo de massa na condição instantânea, exceto para a relação altura/lado igual a 5,3 e seção transversal de descarga $42,25 \mathrm{~cm}^{2}$, visto que houve formação de arco coesivo, conforme se verifica na Figura 5. A não ocorrência do fluxo instantâneo para esta relação altura/lado se deve ao fato do teor de umidade ser considerado alto e possuir grande quantidade de finos, associada às dimensões do orifício de descarga.

Produto: ração 2 e relação altura/lado: 1,76; 3,5 e 5,3: A ração 2 obteve fluxo de massa com o tempo instantâneo, para os três orifícios de descarga e as três relações altura/lado,

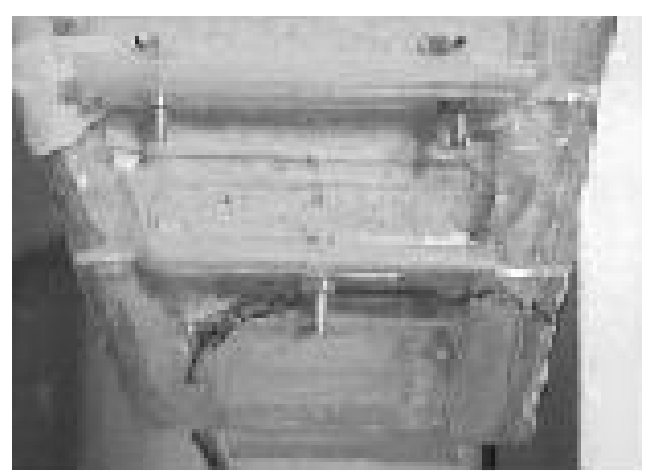

Figura 5. Formação do arco coesivo para a ração 1 , com $\mathrm{H} / \mathrm{L}=$ 5,3 e STD $1=42,25 \mathrm{~cm}^{2}$ 
conforme se observou nas Figura 6 (A, B e C), que registraram o movimento do produto em função do tempo. Um fato a se ressaltar é que a tremonha tronco piramidal com descarga excêntrica proporcionou fluxo de massa. Bandeira (1997) realizou ensaios com ração usando tremonha tronco piramidal com descarga concêntrica e obteve a formação de arco coesivo e efeito tubo. A ração 2 indicou melhor comportamento de fluxo instantâneo em relação à ração 1, para as três relações altura/ lado e os três orifícios de descarga, mesmo possuindo teor de gordura superior, cujo comportamento se deve, sem dúvida, ao fato de que a ração 2 apresentou maiores percentuais retidos nas peneiras com malhas de 1,0,0,54 e 0,42 mm, que a ração 1 , somando-se a isto o teor de umidade, que foi inferior.

A.

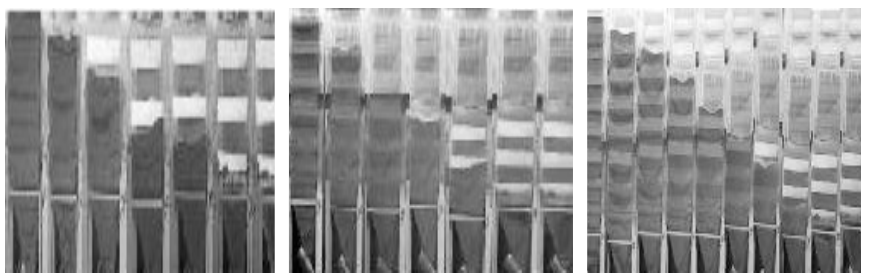

B.

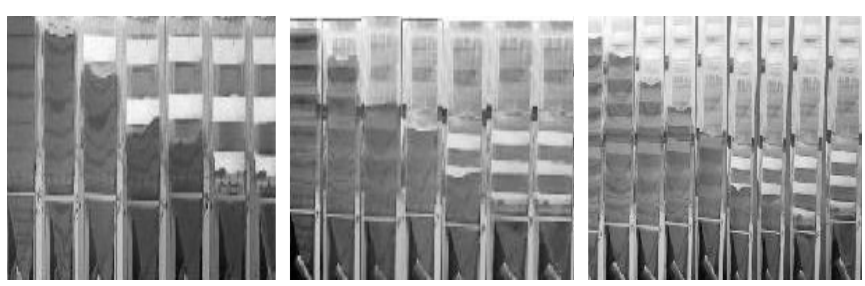

C.

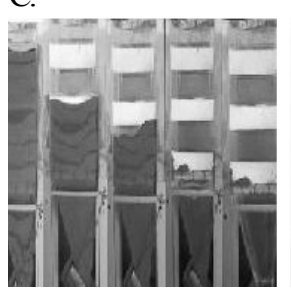

$\mathrm{H} / \mathrm{L}=1,76$

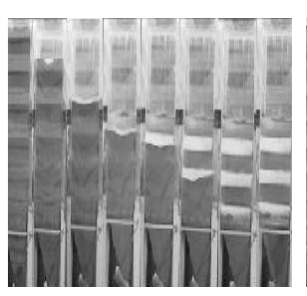

$\mathrm{H} / \mathrm{L}=3,5$

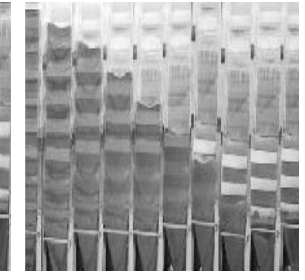

$\mathrm{H} / \mathrm{L}=5,3$
Figura 6. Fluxo de massa para a ração 2 -seção transversal de descarga $=42,25(A), 64(B)$ e $100 \mathrm{~cm}^{2}(C)$, para relações altura lado $(\mathrm{H} / \mathrm{L})$

\section{Fluxo com consolidação de $12 \mathrm{~h}$}

Produto: ração 1 (TG $=6,99 \%$ ), relação altura/lado: 1,76 , 3,5 e 5,3: Com o aumento do tempo de consolidação para $12 \mathrm{~h}$, notou-se que a ração 1 não fluiu para as três relações altura/ lado e os três orifícios de descarga. Com a consolidação, as forças coesivas que agem entre as partículas do produto crescem e dificultam o fluxo e impedem, também, que ele ocorra com a formação de arcos coesivos, fato observado nos testes realizados, conforme indica a Figura 7 (A e B). A medida em que o orifício de descarga era aberto, formava-se o arco coesivo, só ocorrendo o fluxo induzido, ou seja, quando este era rompido.

Para a seção transversal de descarga de $100 \mathrm{~cm}^{2}$ contatouse que a ração 1 só não fluiu para a relação altura/lado de 5,3, porque ocorre acréscimo no estado de tensões com o aumento da altura do silo. Este acréscimo de tensões nas paredes do silo e da tremonha permite a formação do arco coesivo e a parada do fluxo. Mesmo não ocorrendo o fluxo com o aumento da relação altura/lado 5,3. para este produto, a seção transversal de descarga que garante fluxo satisfatório, mesmo com o aumento do tempo de armazenamento, foi a de $100 \mathrm{~cm}^{2}$.

Produto: ração 2 e relação altura/lado: 1,76, 3,5 e 5,3: Para a seção transversal de descarga com $42,25 \mathrm{~cm}^{2}$ não se deu o fluxo de massa para as três relações altura/lado, devido à formação de arcos coesivos. A seção transversal de descarga
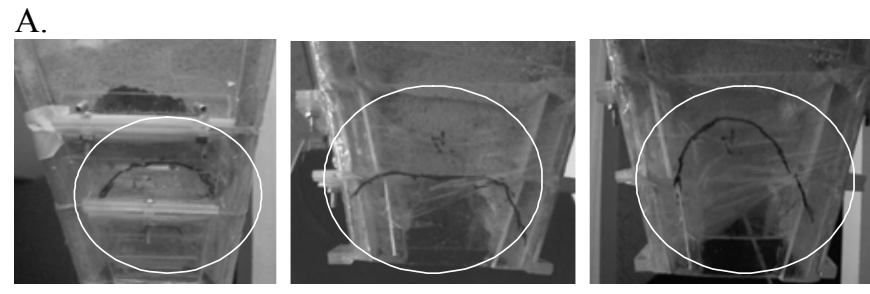

\section{B.}

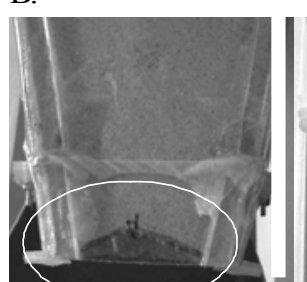

$\mathrm{H} / \mathrm{L}=1,76$

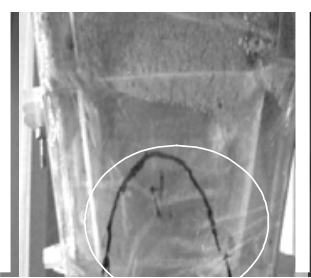

$\mathrm{H} / \mathrm{L}=3,5$

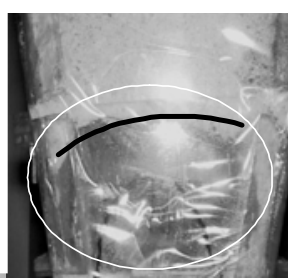

$\mathrm{H} / \mathrm{L}=5,3$
Figura 7. Formação do arco coesivo para ração $1, \mathrm{~T} 2=12 \mathrm{~h}$, com STD1 = 42,25 (A) e $64 \mathrm{~cm}^{2}(B)$, para relações altura lado $(\mathrm{H} / \mathrm{L})$

de $64 \mathrm{~cm}^{2}$, proporcionou fluxo de massa somente para a relação altura/lado 1,76; para as demais, se deu o mesmo fenômeno do caso anterior enquanto para a seção transversal de $100 \mathrm{~cm}^{2}$ aconteceu o fluxo de massa para as três relações altura/lado.

Nas situações em que houve a formação do arco coesivo, ocorria também o fluxo de massa, logo depois da quebra do arco. Não se observou o efeito tubo em nenhum dos testes realizados, ao contrário de Bandeira (1997) que verificou, em ensaios com rações avícolas, a formação do tubo para uma ração cujo teor de gordura era de $7,11 \%$. As rações estudadas neste trabalho possuem teores de gordura variando de 6,99 a $7,24 \%$, superiores, portanto, aos de Bandeira (1997) e com tremonha tronco piramidal com orifício de descarga excêntrico.

\section{CONCLUSÕES}

1. A ocorrência ou não do fluxo foi influenciada pela área da seção transversal do orifício de descarga, tempo de armazenamento e pela relação altura/lado.

2. Com o aumento do tempo de armazenamento de $0 \mathrm{~h}$ para $12 \mathrm{~h}$ verificou-se, para as duas rações, a formação de arcos coesivos.

3. Das três áreas de seções transversais de descarga analisadas, a que proporcionou fluxo de massa sem a formação de arco coesivo foi a de $100 \mathrm{~cm}^{2}$.

4. A tremonha tronco piramidal com excentricidade 0,25 , proporcionou fluxo de massa para ração avícola com seção transversal de $100 \mathrm{~cm}^{2}$. 
5. A excentricidade da tremonha facilitou a ocorrência do fluxo de massa.

6. No projeto de silo para armazenamento de ração avícola recomenda-se a utilização de excentricidades de $0,25 \mathrm{em}$ tremonhas tronco piramidal, uma vez que estas proporcionaram o fluxo de massa.

\section{AGRADECIMENTOS}

À industria de ração GuarAVES, pelo fornecimento de uma das rações utilizadas neste trabalho; à Coordenação de Aperfeiçoamento de Pessoal de Ensino Superior - (CAPES), pela bolsa de estudos concedida, e ao Conselho Nacional de Desenvolvimento Científico e Tecnológico - $(\mathrm{CNPq})$, pelo apoio financeiro.

\section{LITERATURA CITADA}

ABEF. Associação Brasileira dos Exportadores de Frango. http://www.abef.com.br. 18/06/2003.

AVISITE. Portal da avicultura com informações qualificadas sobre avicultura industrial. http://www.avisite.com.br. 22/ 08/2003.

Bandeira, I.S.A. Análise de fluxo de ração e farelo de trigo em silos prismáticos industriais. Campina Grande: UFPB, 1997. 71p. Dissertação Mestrado

Benink, E.J. Flow and stress analysis of cohesioless bulk materiales in silos related to codes. Enschede: Universiteit Tweste, 1989. 162p. Doctoral Thesis

BMHB - British Materials Handling Board. Draf cade of practice for design of silos, bins, bunkers and hoppers.2. ed. London: Besks Editora, 1985. 101p.

Bokhoven, W.H.; Lohnes, R.A. Preconsolidation effects on flow characteristics of soybean. Transactions of the American Society of Agricultural Engineers, St. Joseph, v.32, n.5, p.1779-1783, 1989 .
Calil Júnior, C. Sobressiones en las paredes de los silos para almacenamiento produtos pulverulentos cohesivos. Barcelona: Universidad Politecnica de Barcelona, 1984.184p. Tese Doutorado

Drescher, A.; Waters, A.J.; Rhoades, C.A. Arching in hoppers: I. Arching theories and bulk material flow properties. Powder Technology, Amsterdam, v.84, n.8, p.165-176, 1995.

Garnier, J. Classification of silo tests. In: Silos fundamentals of theory, behaviour and design. 1. ed. London : Routledge Editora, v.único, p.612-619, 1998.

Jenike, A. W. Storage and flow of silos. 1. ed. Salt Lake City: Eighth Printing Editora, 1964, 196p.

Milani, A.P. Determinação das propriedades de produtos armazenados para projetos de pressões e fluxo em silos. São Carlos: EESC/USP, 1993. 272p. Tese Doutorado

Nascimento, J.W.B. Estudo dos silos metálicos prismáticos para fábricas de ração. São Carlos: EESC/USP, 1996. 152p. Tese Doutorado

Nóbrega, M.V. Análise de vazão e fluxo de ração avícola em silos prismáticos com descarga excêntrica. Campina Grande. UFCG, 2003. 88p. Dissertação Mestrado

Nogueira Júnior, S.; Negri Neto.A.; Nogueira, E.A. Perspectivas de consumo de alimentos para animais em 2002. http:// www.iea.sp.gov.br/ana\%2Doli0602.htm.05/11/2002.

Ooi, J.Y.; Chen, J.F.; Rotter, J.M. Measurement of solids flow patterns in gypsum silo. Edinburgh, v.99, n.10, p.272-284. 1998.

Randall, E. L. Improved method for fat and oil analysis by a new process of extraction. Journal of the AOAP, v.57, n.5, p.1167-1168, 1974.

Roberts, A.W. Storage, flow and handling of bulk solids. The University of Newcastle. Australia, v.único, p.103-135, 1987.

Rotter, J.M. Challenges for the future in numerical simulation. In: Silos: fundamentals of theory, Behaviour and design. v. único. London: Routledge Editora, 1998. p.584-604

Zhong, Z.; Ooi, J.Y.; Rotter, J.M. The sensitivity of silo flow and wall stresses to filling method. Engineering Structures, Edinburgh, v.23, n.7, p.756-767.2001. 